Industrial Health, 1983, 21, 67-77.

\title{
A New Technique for Generating Heavy Metal Fumes with High Melting Point
}

\author{
Fumio SERITA \\ National Institute of Industrial Health, 21-1, Nagao 6-chome, \\ Tama-ku, Kawasaki-shi, Kanagawa 214, Japan
}

(Received November 16, 1982 and in revised form March 7, 1983)

\begin{abstract}
There are many kinds of fumes containing heavy metals in the working area. They sometimes have bad effects on the living body. It is important to determine their particle size distribution for considering the effects of those metals on health, together with measuring their amounts. For this purpose, it is necessary to generate fumes which are suitable to use. However, effective methods for generating fumes of heavy metals with high melting points have not been developed.

In this study we attempted to determine whether the plasma flame metal sprayer can be used as a fume generator. The size distribution, particle form and amounts of the generated fumes were determined for the iron fume which were generated with this instrument under the various conditions. The fume was to consist of coagulated fine particles and dispersed globular particles. Our attempt extended to the generation of fumes consisting not only of one kind of metal but also of two kinds of metal. It was also found that fumes having the required radio might be generated by controlling the ratio of the metals in the powder mixture.

We conclude that this instrument might be suitable for generating fumes of heavy metals in the laboratory.
\end{abstract}

Key words: Fume generator-Fume of heavy metal--Plasma flame metal sprayer-Fume-Iron fume-Plasma flame

\section{INTRODUCTION}

In most working areas where metals are used, many fumes containing heavy metals are released into the air and they are harmful for workers. A technique for generating heavy metal fumes in the laboratory is necessary for studying their effects on the health of humans and experimental animals, and to develop methods for measuring them.

In the case of some heavy metals with low melting points such as lead and cadmium, a method for generating metal fumes was developed by Homma ${ }^{1)}$ and these generated fumes have been used in many experiments ${ }^{2-9)}$. However we have 
no proper method for generating fumes of other heavy metals such as iron, chromium, manganese, nickel and vanadium at present.

In this study we attempted to determine whether the plasma flame metal sprayer which has been used for coating fabricating materials in industry can be used as a fume generator for heavy metals with high melting points in the laboratory, and, if it could be used as a fume generator, under what conditions it generates fumes adequate for experiments.

\section{Apparatus AND EXPERIMENT}

\section{Apparatus}

In industry, the plasma flame metal sprayer is used in the spraying process in order to improve the chemical-proof and/or heat-proof properties of fabricating materials.

In this instrument, metal powder is used as the spraying material. Since many kinds of powder can be purchased along with this instrument, fumes are generated easily from these powders. Moreover, a fume containing several metal elements can be obtained by mixing separate powders of those elements. The powders are blown into a stream at a temperature over $10,000^{\circ} \mathrm{C}^{10)}$, which is high enough to melt and vaporize even heavy metals with high melting points such as iron, chromium and nickel.

The apparatus used in the experiments consists of a chamber with a volume of $4.3 \mathrm{~m}^{3}$ and a plasma flame metal sprayer type 7M METCO (USA), as shown in Figure 1. The plasma flame gun (5) in this apparatus is supplied with argon gas from a cylinder (2), and with electricity by a D.C. power supply (1). A schematic diagram of the plasma flame gun is shown in Figure $2^{11)}$. A molecule of argon gas supplied to the plasma flame gun becomes ions in the arc stream between electrodes.

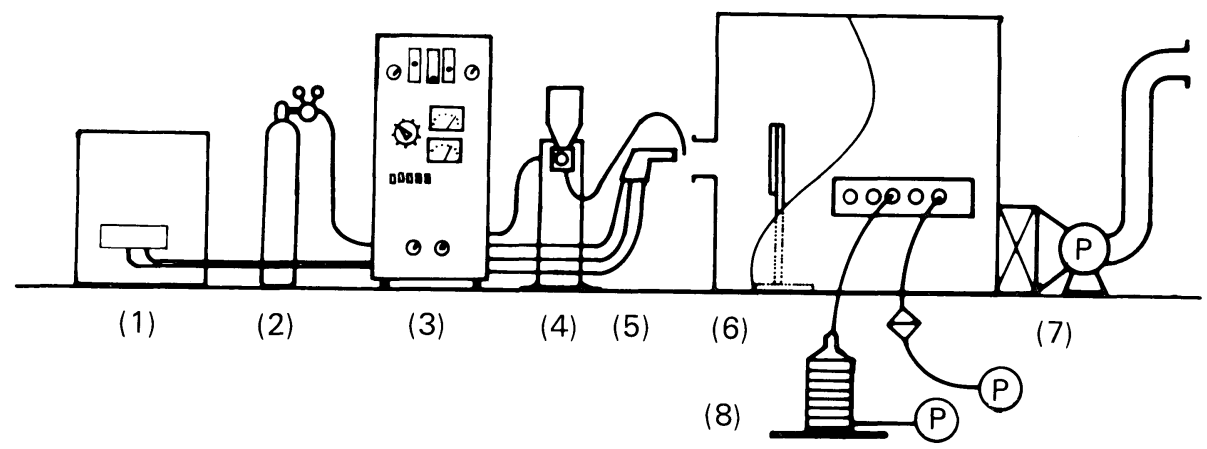

Fig. 1. Schematic diagram of metal fume generating apparatus.
1. D.C. power supply
2. Cylinder of argon gas
3. Control console
4. Powder feeder
5. Plasma flame gun
6. Aerosol chamber
7. Ventilator
8. Aerosol samplers 


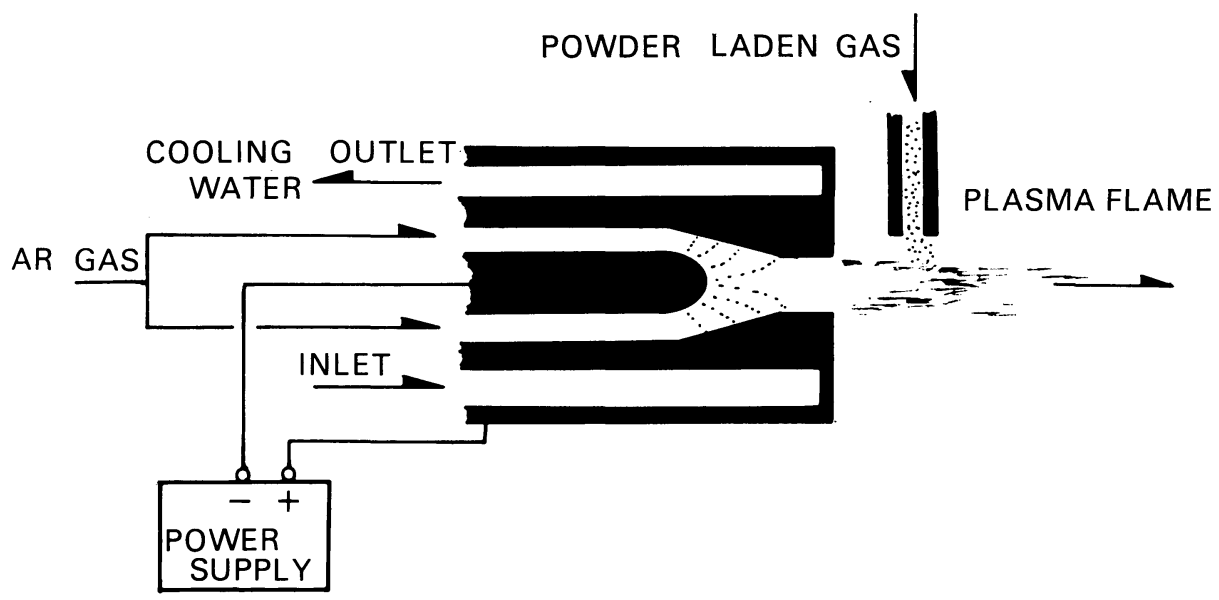

Fig. 2. Schematic diagram of plasma flame gun.

This is called plasma. The plasma is formed continuously, and when it blows up through the nozzle of the gun it makes the stream have a high velocity and high temperature.

In the experiment, plasma flame is blown into the chamber. If the metal powder is thrown into the plasma flame, the metal powder particles are instantly melted and vaporized by sufficient heat from the plasma. Then, vapor from the greater

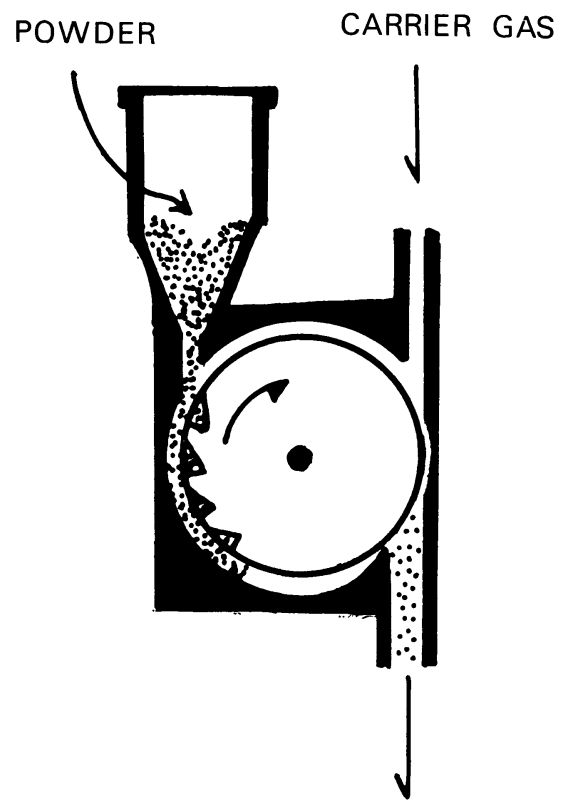

Fig. 3. Schematic diagram of powder feeder. 
part of the heated metal powder is cooled in the open air and becomes the fume. Therefore, a lot of fume and a part of the unvaporized powder are conveyed into the chamber.

In the chamber, as shown in Figure 1-(6), the flat plate, into which the large particles collide and are removed from the stream, is set up $50 \mathrm{~cm}$ from the nozzle; moreover, it defuses the hot stream to prevent heat damage to the chamber walls. On the side wall of the chamber, there are sampling holes. A ventilator (7) is attached at the other side of the chamber, in order to clean the air in the chamber after measurement.

A powder feeder (4) is used to feed the powder into the plasma flame. A schematic diagram of the powder feeder is shown in Figure 3. The powder in the hopper is taken up by notches on the circumference of the rotator, and then carried into the flow of carrier gas with rotation of the rotator. The powder-laden gas which moves in a tube is supplied into the plasma flame near the nozzle of the gun. The quantity of powder can be controlled by changing the rotation rate.

\section{Experiment}

As the plasma flame metal sprayer used in these experiments is usually used for industrial machines, it can generate a large amount of fume in an instant. So if the fume is sampled with the apparatus in operation, the concentration in the chamber becomes so high that the bad effect on fume measurement caused by coagulation cannot be neglected. To avoid this phenomenon, the plasma flame metal sprayer was operated for only one minute before the sampling (see Table 1).

A) Reproducibility of the amount and the particle size distribution of the fume

Five cycles of fume generation and sampling were carried out under the conditions shown in Table 2. The fume was sampled with a cascade impactor to

Table 1. Procedure for metal fume generation by the plasma flame sprayer

Set the amount of metal powder to be provided.

Set the flow rate of the argon gas to form the plasma flame. $(47 \sim 188 \mathrm{l} / \mathrm{min})$

Ignition. (Discharging start: initial current 200 250 A)

Increase the current to the preset point. (300 1200 A)

Formation of stable plasma flame.

Start providing the powder.

Fume generation for $1 \mathrm{~min}$.

Stop providing the powder.

Decrease the current.

Turn off the flame.

Stop the argon gas.

Leave the fume as it is.

Start the metal fume sampling.

* It takes 1 minute from the time the provision of powder is stopped to the beginning of sampling. 
Table 2. Operating conditions of plasma flame sprayer for generation of metal fume

\begin{tabular}{lrcc}
\hline & & (a) & (b) \\
\hline Current & {$[\mathrm{A}]$} & 500 & 600 \\
\hline Voltage & {$[\mathrm{V}]$} & 46.5 & 47.0 \\
\hline Argon gas flow rate & {$[l / \mathrm{min}]$} & 142 & 142 \\
\hline Iron powder 200 mesh & $12 \mathrm{~g} / \mathrm{min}$ & & \\
\hline
\end{tabular}

measure the particle size distribution, and the weight concentration of the fume in the chamber was determined. A Teflon-treated glass fiber filter (Pallflex T60A20) was put on an aluminium plate of each stage of the dascade impactor as an impaction plate. A filter of the same type was used as a backup filter. The sampling period was 60 minutes.

B) The relationship between the generating conditions and the particle size distribution of the fume

The plasma flame was set up to generate the iron fume under the four different conditions described in Table 3. Selected values for the experimental conditions were the power densities, which were given to the argon gas by the electric arc, calculated from the flow rate of argon gas and discharging current and voltage between the electrodes. The iorn fume was caught on the impaction plates of the cascade impactor for 20 minutes, and on the filter of the low volume air sampler for 5 minutes after fume generation, and the cumulative size distributions of the fumes under each condition were obtained. The rate of supplying the iron powder under 200 mesh was $23 \mathrm{~g} / \mathrm{min}$.

C) The relationship between the ratio of the metal element component of the metal powder and of the fume

In order to determine the relationship between the ratio of the metal element component of the fume and of the material powder mixtures of manganese and iron powders at ratios of $1: 1,1: 4,1: 16$, and $1: 50$ and mixtures of chromium and iron powders at ratios of $4: 1,2: 1,1: 1$ and $1: 4$ were prepared. The chromium powder was of 175 mesh and was produced for the spraying process by Metco

Table 3. Experimental conditions for fume generation using iron powder. Combinations of the flow rate of argon gas and discharging current and voltage

\begin{tabular}{lrrrrr}
\hline & $(\mathrm{a})$ & $(\mathrm{b})$ & \multicolumn{1}{c}{$(\mathrm{c})$} & \multicolumn{1}{c}{$(\mathrm{d})$} \\
\hline Flow rate of argon gas $[l / \mathrm{min}]$ & 47 & 94 & 142 & 188 \\
\hline Current & {$[\mathrm{A}]$} & 600 & 600 & 600 & 600 \\
\hline Voltage & {$[\mathrm{V}]$} & 33 & 38 & 47 & 59 \\
\hline Power density & {$\left[\mathrm{kW} / \mathrm{m}^{3}\right]$} & 7.0 & 4.0 & 3.3 & 3.1 \\
\hline
\end{tabular}


Inc. The manganese and iron powders, of less than 325 mesh, were purchased for reagent use from Soekawa Co. The generating conditions were as follows: The flow rate of argon gas was 47 liters/min, and the discharging current was $600 \mathrm{~A}$. The fume was collected on a 47- $\phi$ quartz fiber filter of a low volume air sampler, and the ratios of iron to manganese and iron to chromium were determined with an energy dispersive $\mathrm{X}$-ray analyzer. Its calibration curve was determined with a mixture of each standard material in advance.

\section{RESUlTS}

Scanning electron microphotographs of the generated fumes are shown in Figure 4. Only lumps of very fine particles and globular particles of a diameter of 3 to $7 \mu \mathrm{m}$ were found. The distribution curves showed the same trend as in Figure 6.

A) Reproducibility of the amount of fume generated and the particle size distribution

The amounts of the fume generated under two experimental conditions are shown in Table 4, and their particle size distribution is shown in Figure 5(a) and (b). When the discharging current was $500 \mathrm{~A}$, the amounts of fume generated
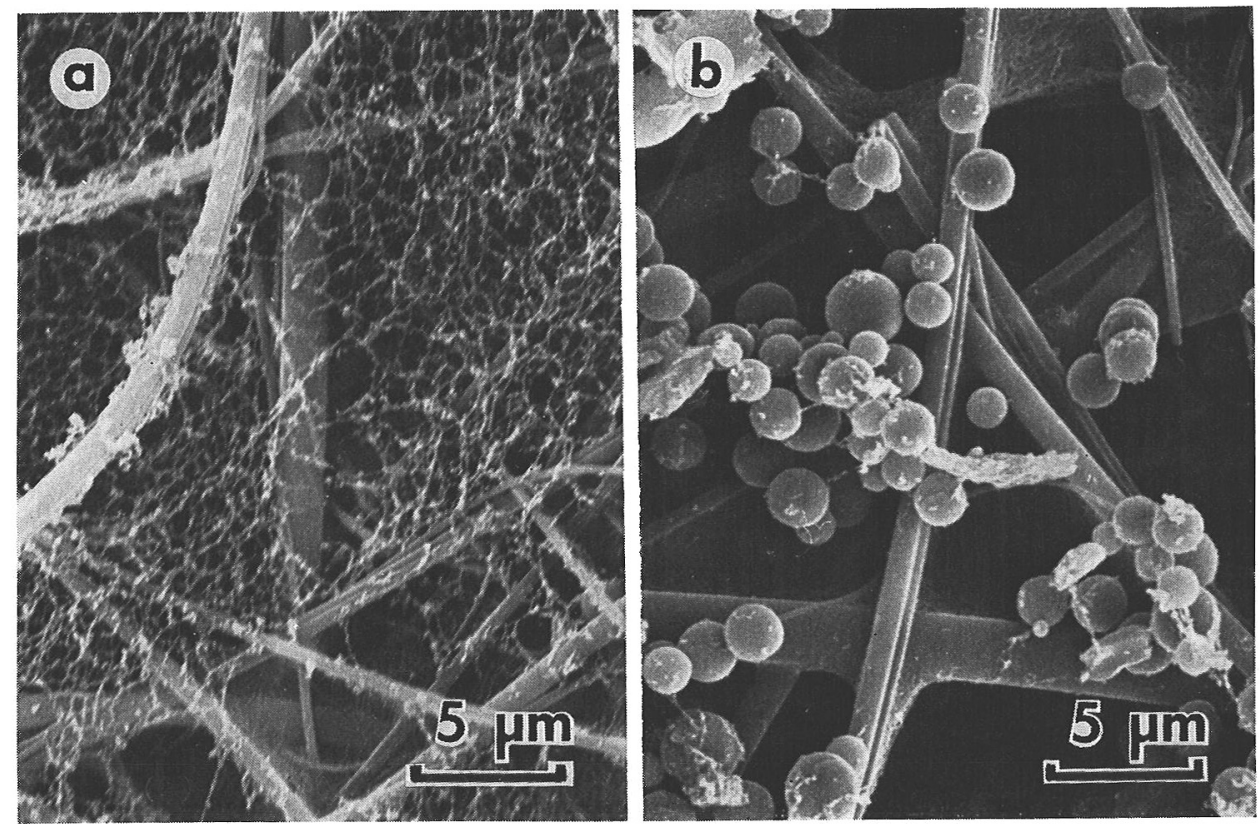

Fig. 4. Scanning electron microphotographs of fumes collected by Andersen sampler.

(a) : Electron micrograph of particles on the back up filter, showing lumps and chains consisting of very fine particles of the fume.

(b) : Electron micrograph of particles from 3 to $7 \mu \mathrm{m}$, showing the dispersed globular particles. 
Table 4. Amount of the fume generated under two different conditions in replicate experiments

\begin{tabular}{cll}
\hline Exp. No. & \multicolumn{1}{c}{$(\mathrm{a})$} & \multicolumn{1}{c}{$(\mathrm{b})$} \\
& $500 \mathrm{~A}$ & $600 \mathrm{~A}$ \\
\hline 1 & $19.8 \mathrm{mg}$ & $16.3 \mathrm{mg}$ \\
2 & 16.9 & 10.3 \\
3 & 14.6 & 12.1 \\
4 & 18.3 & 16.1 \\
5 & 16.4 & 15.6 \\
\hline
\end{tabular}
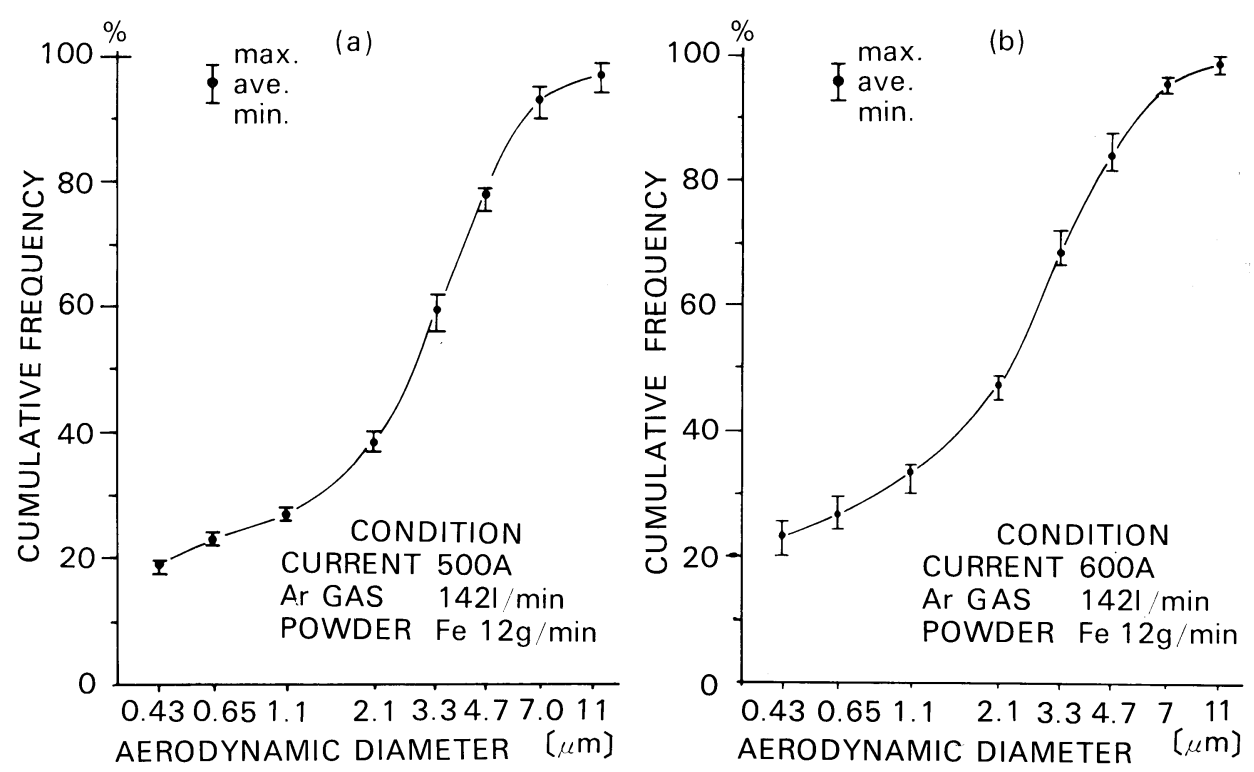

Fig. 5. Reproducibility of cumulative size distribution of five measurements under the same conditions. The curves of (a) and (b) are their averages.

ranged from 14.6 to $19.8 \mathrm{mg}$ and when the current was $600 \mathrm{~A}$, from 10.3 to $16.3 \mathrm{mg}$. Though those values were very scattered in this way, five distribution curves for each condition were similar.

B) The relationship between the generating condition and the particle size distribution of the fume

In Figure 6, the effect of the power density which is given to argon gas of unit volume by an electric arc on the cumulative frequency of particle size distribution is shown. The amounts of fumes generated are shown in Table 5. In case of a power density of $7 \mathrm{~kW} / \mathrm{m}^{3}$ the backup filter set on the cascade impactor caught over $50 \%$ of the total deposited weight of the fume. The fume particles collected on the backup filter were less than $0.43 \mu \mathrm{m}$ in aerodynamic diameter and the weight ratio of particles from 3 to $7 \mu \mathrm{m}$ (globular particles) to whole particles was about $15 \%$. As the power density decreased, the weight ratio of particles 
Table 5. The amounts of fume generated at two different particle size ranges

\begin{tabular}{ccclll}
\hline $\begin{array}{c}\text { Power } \\
\text { density }\end{array}$ & Total & Range from 3 to $7 \mu \mathrm{m}$ & \multicolumn{2}{c}{ Less than $0.43 \mu \mathrm{m}$} \\
\hline $\mathrm{a}\left(7.0 \mathrm{~kW} / \mathrm{m}^{3}\right)$ & $12.61 \mathrm{mg}$ & $2.11 \mathrm{mg}$ & $16.7 \%$ & $7.12 \mathrm{mg}$ & $56.5 \%$ \\
$\mathrm{~b}\left(4.0 \mathrm{~kW} / \mathrm{m}^{3}\right)$ & 9.36 & 3.47 & 37.1 & 3.42 & 36.5 \\
$\mathrm{c}\left(3.3 \mathrm{~kW} / \mathrm{m}^{3}\right)$ & 8.51 & 4.03 & 47.4 & 2.12 & 24.9 \\
$\mathrm{~d}\left(3.1 \mathrm{~kW} / \mathrm{m}^{3}\right)$ & 9.16 & 5.08 & 55.5 & 1.63 & 17.8 \\
\hline
\end{tabular}

from 3 to $7 \mu \mathrm{m}$ to whole particles increased, and that of particles less than $0.43 \mu \mathrm{m}$ decreased. When the power density of argon gas was $3.1 \mathrm{~kW} / \mathrm{m}^{3}$, as shown in Figure 6 the weight ratio of the globular particles to whole particles reached $40 \%$, and that of coagulated particles became less than $20 \%$. The parts of these curves with gentler inclination (size 0.43 to $3 \mu \mathrm{m}$ ) show that there were few particles of this size range. In other words there was a change in the ratio of the constitution between coagulated fine particles and globular particles, but no change in the mean diameter of the globular particles and the fine primary particles.

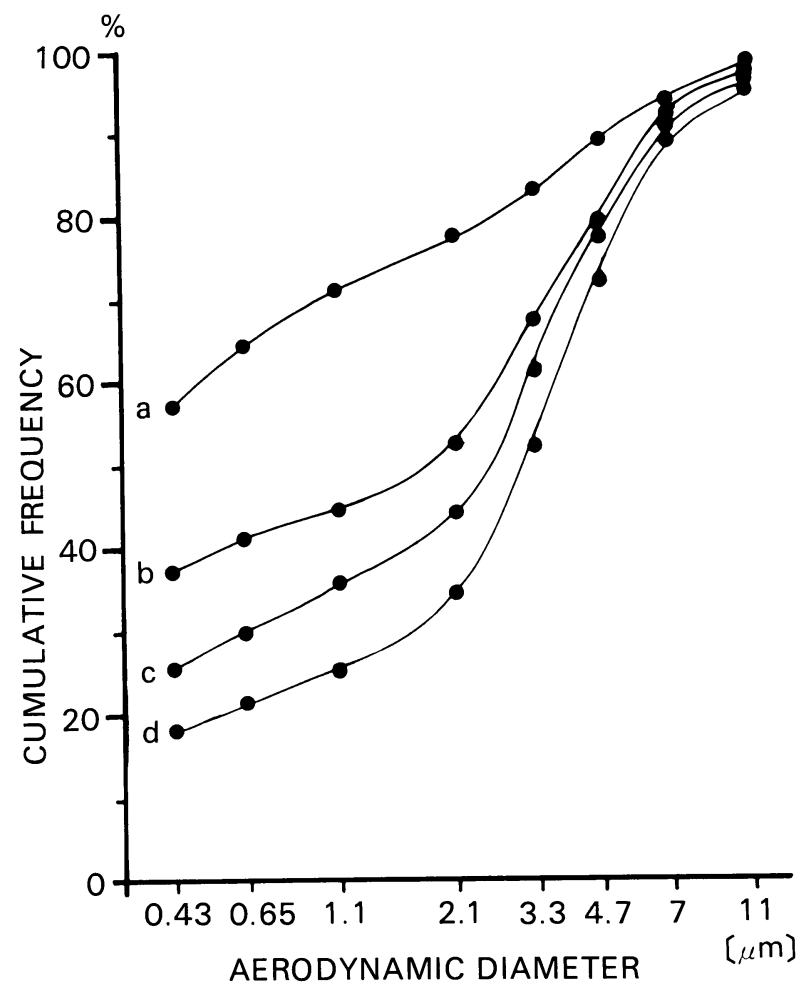

Fig. 6. Effect of power density on the cumulative size distribution.
a : $7.0\left[\mathrm{~kW} / \mathrm{m}^{3}\right]$
b : $4.0\left[\mathrm{~kW} / \mathrm{m}^{3}\right]$
c: 3.3
d: 3.1 
C) The relationship between the ratio of the metal element components of the material and of the fume

Fumes consisting of two kinds of metal elements could be generated from a mixed powder. The ratios of the metal element components of the fume were not the same as that of the mixed powder. The ratio of the metal element components of the fume depended on the ratio of the elements in the mixture, as shown in Table 6. When these data were plotted on logarithmic graph paper they formed straight lines, as shown in Figure 7(a) and (b).

Table 6. The ratio of the component metal elements of the generated fumes.

\begin{tabular}{lcccc}
\hline \multicolumn{2}{c}{ Mn/Fe } & & \multicolumn{2}{c}{$\mathrm{Cr} / \mathrm{Fe}$} \\
\cline { 5 - 5 } Powder & Fume & & Powder & Fume \\
\hline $1 / 1$ & 5.4 & & $4 / 1$ & 1.0 \\
$1 / 4$ & 2.3 & & $2 / 1$ & 0.58 \\
$1 / 16$ & 0.82 & & $1 / 1$ & 0.35 \\
$1 / 50$ & 0.35 & & $1 / 4$ & 0.12 \\
\hline
\end{tabular}
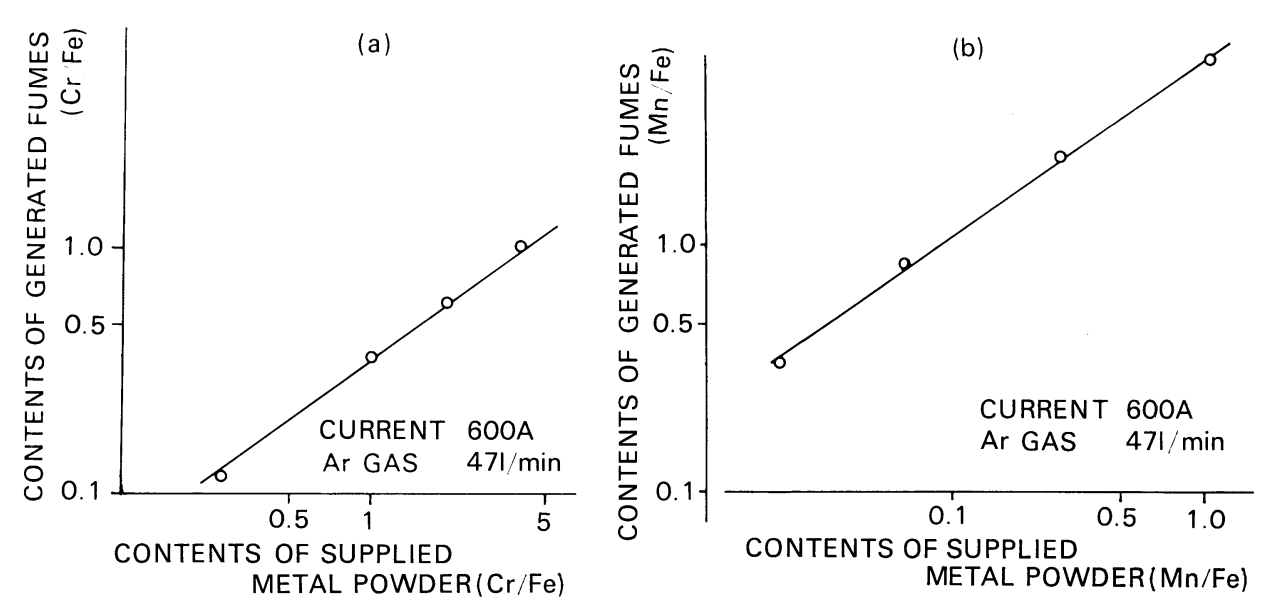

Fig. 7. The relationship between the ratios of the metals in the mixed powders and of the metal element components of the fume.

\section{Discussion}

The reproducibility of the particle size distribution of the fume was confirmed, but the amount of fume generated varied largely. This fluctuation was especially pronounced when a smaller amount of powder was supplied to keep the concentration in the chamber as low as possible. It was probably caused by variation in the amount of powder supplied.

By means of analysis with an X-ray diffractometer it was found that the fume deposited on the quartz fiber filter was iron oxide. On the other hand, specific 
gravity of the globular particles caught by the cascade impactor was estimated to be 5.2 by using the ratio between the aerodynamic median diameter obtained by the cascade impactor and the count median diameter obtained from electron micrographs. Since specific gravities of $\mathrm{Fe}, \mathrm{FeO}_{2}, \mathrm{Fe}_{2} \mathrm{O}_{3}(\alpha), \mathrm{Fe}_{2} \mathrm{O}_{3}(\gamma)$, and $\mathrm{Fe}_{3} \mathrm{O}_{4}$ are 7.0, 5.7, 5.03, 5.1 5.2 and 5.16, respectively, it is presumed that the fume was formed from iron oxides and contained no metal iron. That is to say, the iron powder was oxidized, in spite of using argon gas as heat source. Perhaps the circumferential air containing $\mathrm{O}_{2}$ was mixed into the plasma flame.

Though the boiling point of chromium and manganese are nearly the same, the ratio of manganese content was much larger than that of chromium content. For example when manganese and chromium respectively were mixed with iron in the powder at a ratio of $1: 1$, the ratio of manganese content cf the fume was 15.4 times as much as the ratio of chromium content of the fume. It is considered that because the manganese power was of finer grain, most of it could be melted and vaporized more easily, and change into the fume. It will be necessary later on to investigate the relation between the amount of the fume generated and the granularity of the powder. Though it has been regarded as difficult so far to generate a fume of metals with high melting points, in this experiment it was obtained easily. Furthermore the possibility was suggested that fumes containing heavy metals such as iron, chromium and manganese at a given ratio might be generated by controlling the ratio of the metals in the powder mixture.

\section{CONCLUSION}

From the results and the discussion above, it may be concluded that the apparatus used in this experiment is suitable for generating fumes of heavy metals with high melting points in the laboratory. In some cases, the questions of instability and an excess amount of fume may arise. These problems will be avoided by improving the powder feeders. However, the plasma flame may produce harmful agents such as ozone, $\mathrm{NO}_{x}$ gases and ultraviolet light. A serious problem in the research on the effects of metal fumes generated from the plasma flame on health, is to eliminate subgenerated materials from the fume generating system.

\section{REFERENCES}

1) Homma, K. (1966). Experimental study for preparating metal fume, Ind. Health, 4, 129.

2) Yoshikawa, H. and Homma, K. (1974). Toxicity of inhaled metallic cadmium fumes in rats, Jap. J. Ind. Health, 16, 212. (in Japanese)

3 ) Homma, K. (1976). Lung retention of metallic fumes. II Lung retention rate of monodespersed spheric metallic fumes in a lung of rats, Jap. J. Hyg., 30, 632. (in Japanese)

4) Homma, K. (1976). Lung retention of metallic fumes. III Lung retention rate of polydispersed irregural fumes in a lung of rats, Jap. J. Hyg., 30, 639. (in Japanese) 
5) Koshi, K., Homma, K. and Sakabe, H. (1975). Responses of alveolar macrophage to metallic fume, Ind. Health, 13, 37.

6) Kyono, H., Homma, K., Nagatani, T., Watanabe, T. and Kawai, K. (1974). Localization of inhaled lead particles in the rat lung, Ind. Health, 12, 49.

7) Homma, K. (1971). Apparatus of the monodispersed aerosol generator, J. Ind. Hyg. Jap., 12, 1. (in Japanese)

8) Yoshikawa, H., Kawai, K., Nozaki, K. and Ohsawa, M. (1976). Japan Environment Agency, Tokyo Japan.

9) Nozaki K. (1979). Experimental study of long-term aerosol inhalation, Jap. J. Ind. Health, 21, 349. (in Japanese)

10) Flame Spray Handbook, Vol. 3, Plasma Flame Process. (1976). METCO Inc., New York.

11) METCO Inc. Instruction Manual of Type 7M Plasma Flame Spray System. P1-P25, METCO Inc., New York. 